\title{
Back Pain in HIV-Infected Patients May Be Due to Spinal Epidural Lipomatosis
}

\author{
Antoine Moulignier ${ }^{1}$, Matthieu Lafaurie ${ }^{2}$, Julien Savatovsky ${ }^{3}$, Marie-Laure Dubreuil-Lemaire ${ }^{4}$ and Cédric Lamirel $^{5}$ \\ ${ }^{1}$ Service de Neurologie, Fondation Adolphe de Rothschild, 75019 Paris, France \\ ${ }^{2}$ Service des Maladies Infectieuses et Tropicales, AP-HP, Hôpital Saint Louis, 75010 Paris, France \\ ${ }^{3}$ Service d'Imagerie Médicale, Fondation Adolphe de Rothschild, 75019 Paris, France \\ ${ }^{4}$ Unité d'Evaluation et de Traitement de la Douleur, Service d'Anesthésie et de Réanimation Chirurgicale. AP-HP, Hôpital Saint Louis, 75010 Paris, France \\ ${ }^{5}$ Département d'Ophtalmologie, Fondation Adolphe de Rothschild, 75019 Paris, France
}

\begin{abstract}
Spinal epidural lipomatosis (SEL) is an abnormal accumulation of normal adipose tissue in the extradural space within the spinal canal that can lead to notable spinal cord compression. It is most commonly reported in patients receiving chronic glucocornticoids. Other causes can include obesity and hypercortisolism. Unusually, SEL may occur in human immunodeficiency virus (HIV)-infected patients, and has been attributed to the lipodystrophy and altered fat metabolism associated with antiretrovirals. We describe a 56-year-old, HIV-infected, non-obese woman with satisfactory immunovirological indices on combined antiretroviral therapy who developed debilitating back pain initially attributed to osteoarthritis. A thorough neurological work-up with magnetic resonance imaging (MRI) led to the diagnosis of rapidly progressive SEL that was not associated with any of its common etiologies.
\end{abstract}

Keywords: HIV; Central nervous system; Epidural lipomatosis; Lipodystrophy; Back pain

\section{Introduction}

Low back pain (LBP) is a frequent complaint of up to $80 \%$ of middleaged persons at some time during their life [1]. Causes are multiple, but only $\sim 20 \%$ of LBP cases can be attributed with reasonable certainty to a pathologic or anatomical entity; disc degeneration accounts for $40 \%$ of them. Determining the LBP etiology is challenging because no significant associations were found between lumbar spine MRI findings and LBP [2]. When a diagnosis of discogenic LBP is initially retained, the risk exits of potentially underestimating rare conditions causing chronic LBP. Since combined antiretroviral therapies (cARTs) were introduced, the spinal cord-disease incidence for HIVinfected patients with good immunovirological indices has decreased dramatically [3]. Other than cARTs' substantial immunological and virological benefits, longstanding HIV-infected patients with prolonged virological suppression may develop lipodystrophy, a rare metabolic complication of antiretrovirals [4]. Spinal epidural lipomatosis (SEL), a rare LBP etiology, should be envisaged for HIV-infected patients, particularly those with HIV-associated lipodystrophy. Indeed, both conditions have been associated with metabolic disturbances, e.g. insulin resistance and hyperlipidemias [4]. Early SEL recognition and appropriate management are important because late diagnosis may lead to permanent and severe disability.

\section{Case Report}

A 56-year-old woman, HIV-positive since 1992, was referred in June 2013 for limb pain worsening over several months, radiating down both legs and severely limiting her walking ability. She had received various cARTs, including nucleoside reverse transcriptase inhibitors (NRTI), nonNRTIs and protease inhibitors (PI), and was currently taking etravirine, raltegravir and tenofovir. She had had $393 \mathrm{CD} 4$ cells $/ \mu \mathrm{L}$, with plasma HIV-RNA at $<50$ copies $/ \mathrm{mL}$, for years. She had suffered from LBP for several years. The first MRI in 2010 showed only disc degeneration; osteoarthritis was diagnosed. Her medical history indicated HIVassociated lipohypertrophy necessitating surgical reduction of neck bumps and swollen breasts. Neurological examination found normal physical strength, sensations and reflexes. In 2013, her physical appearance was good, with a body mass index (BMI) of $24 \mathrm{~kg} / \mathrm{m}^{2}$. However, a new spinal MRI revealed lumbar epidural lipomatosis and lumbar stenoses (Figure 1A-C). Somatosensory-evoked potentials and transcranial motor-evoked potentials were normal. Although not obese, she started a low-calorie diet, lost $15 \mathrm{~kg}$, and her BMI fell to $18 \mathrm{~kg} / \mathrm{m}^{2}$ within 10 months. Pain relief was satisfactory. Her March 2014 MRI showed markedly regressed lipomatosis and stenoses (Figure 1D) that persisted 1 year later.

\section{Discussion}

SEL, a rare condition defined by the pathological overgrowth of normal adipose tissue in the thoracic and lumbosacral epidural spaces, causes nerve-root and spinal cord compression $[5,6]$. SEL-onset features are insidious and non specific, but delayed diagnosis may lead to severe functional disabilities. Back pain is the most common first symptom, followed by weakness of the lower extremities, and ataxia [7,8].

Differential diagnoses of chronic LBP in HIV-infected patients are broad and can be grouped into 4 main categories: spinal cord pathologies (compressive, vascular, immune-mediated and infectious diseases), radicular lesions (mainly disc herniation and spinal stenosis), referred pain (visceral diseases) and discogenic LBP. Spinal cord disease was frequent in the pre-cART era but is currently much less common [4]. Hence, the degree of immunosuppression is a reliable parameter orienting cord-dysfunction diagnosis. In a context of immunodepression and cord dysfunction, opportunistic infections and tumors, e.g. lymphoma, should be evoked first [4]. Patients

*Corresponding author: Antoine Moulignier, Service de Neurologie, Fondation Adolphe de Rothschild, 25, rue Manin, 75019 Paris, France. Tel: +33 (0)1 480368 60; Fax:+33 01480368 59; E-mail: amoulignier@fo-rothschild.fr

Received September 03, 2014; Accepted September 25, 2015; Published September 30, 2015

Citation: Moulignier A, Lafaurie M, Savatovsky J, Dubreuil-Lemaire ML, Lamire C (2015) Back Pain in HIV-Infected Patients May Be Due to Spinal Epidural Lipomatosis. J AIDS Clin Res 6: 505. doi:10.4172/2155-6113.1000505

Copyright: (c) 2015 Moulignier A, et al. This is an open-access article distributed under the terms of the Creative Commons Attribution License, which permits unrestricted use, distribution, and reproduction in any medium, provided the original author and source are credited. 

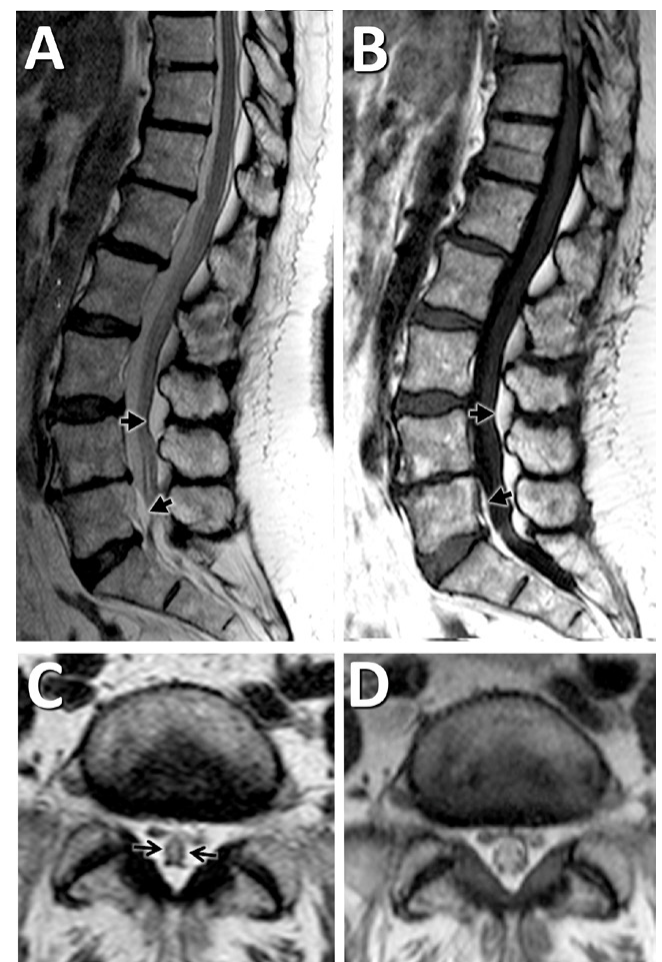

Figure 1: Successive MRIs. Initial sagittal T2-weighted (A), sagittal T1weighted (B) and axial T2-weighted images (C). Spinal canal stenosis (arrows), caused by epidural fat compression, is visible, particularly at L5-S. Follow-up axial T2-weighted MRI 9 months later (D): note the marked lipomatosis and spinal stenosis attenuation.

with vacuolar myelopathy generally have slowly progressive and typically painless myelopathy [4]. For those with good virological and immunological controls, differential cord-dysfunction diagnoses are the same as for the general population, and principally include degenerative conditions, encapsulated spinal lipomas, herniated disc and vertebral body metastases.

Patients' history and physical findings do not predict the etiology but are important to localize the lesion to the specific root or cord level and guide imaging. Spinal MRI, the most sensitive and specific tool for detecting SEL, shows increased signal intensity on non-contrast $\mathrm{T} 1$ sequences and intermediate signal intensity on T2 sequences. Axial imaging shows fat causing circumferential compression of the dural sac, known as the "Y-sign", which is pathognomonic of lumbar epidural lipomatosis. The best diagnostic criterion of SEL is epidural fat thicker than $6 \mathrm{~mm}[8]$.

SEL mainly reflects long-term administration of exogenous steroids, associated with or independent of systemic diseases, or endocrinopathies producing excessive endogenous corticosteroids, and less frequently, with severe obesity [6,7]. Its pathogenesis is unknown but adipose-tissue overgrowth in the epidural space suggests the hypothetical involvement of insulin secretion secondary to the glucocorticoid-induced blood-glucose elevation.

Lipodystrophy is characterized by fat accumulation (hypertrophy) in one or more anatomical sites (abdomen, dorsocervical area, breasts) or fat loss (atrophy) mainly in the face, buttocks and extremities or mixed lipodystrophy (combination of lipoatrophy and lipohypertrophy). Its broad prevalence range, $11 \%-83 \%$ of individuals receiving cART, is mainly attributed to no consensus regarding the reference diagnosis method [4]. Risk factors include older age, greater HIV-infection severity, increased viral load low CD4 count [6,7,9]. Although multiple parameters dependent on virological, genetic and individual immunological factors affect its pathogenesis, HIV infection itself and long-term exposure to cARTs (thymidine analogs or NRTIs and PIs) are mostly implicated [4]. The dyslipidemia, insulin resistance, increased cardiovascular disease risk and cosmetic impact of lipodystrophy complicate the management of HIV-infected patients [4].

Only a few HIV-infection-associated SEL have been reported so far $[5-7,9,10]$ and attributed to cART-induced lipodystrophy in the absence of glucocorticoids $[6,7,9,10]$. One case of HIV-associated SEL was clearly linked to obesity [6] but BMIs were not reported for the others.

SEL treatment depends on cord-compression severity. Conservative treatment options include weight loss for overweight patients, combined with physical rehabilitation and pain management [8]. Weight loss may be beneficial even for non-obese patients, as for our case, and should be recommended systematically. Severe cord compression or weightloss inefficacy requires decompressive laminectomy with epidural fat resection. SEL is probably more common in HIV-infected patients than currently reported and may frequently be missed on plain radiographs and computed-tomography scans usually obtained for LBP.

\section{Acknowledgements}

The authors thank Janet Jacobson for editorial assistance.

\section{Declaration of Conflicting Interests}

The authors declared no potential conflicts of interest with respect to the research, authorship, and/or publication of this article.

\section{Funding}

The authors received no financial support for the research, authorship, and/or publication of this article.

\section{References}

1. Woolf AD, Pfleger B (2003) Burden of major musculoskeletal conditions. Bull World Health Organ 81: 646-656.

2. Suri P, Boyko EJ, Goldberg J, Forsberg CW, Jarvik JG (2014) Longitudinal associations between incident lumbar spine MRI findings and chronic low back pain or radicular symptoms: retrospective analysis of data from the longitudinal assessment of imaging and disability of the back (LAIDBACK). BMC Musculoskelet Disord 15: 152

3. Cho TA, Vaitkevicius $H(2012)$ Infectious myelopathies. Continuum (Minneap Minn) 18: 1351-1373.

4. da Cunha J, Ferreira Maselli LM, Bassi Stern AC, Spada C, Bydlowski SP (2015) Impact of antiretroviral therapy on lipid metabolism of human immunodeficiency virus-infected patients: Old and new drugs. World J Virol 4: 56-77.

5. Vince GH, Brucker C, Langmann P, Herbold C, Solymosi L, Roosen K (2005) Epidural spinal lipomatosis with acute onset of paraplegia in an HIV-positive patient treated with corticosteroids and protease inhibitor. Spine 30: E524-E527.

6. Billings F, Hoyt MR (2012) Epidural lipomatosis causing new debilitating back pain in a patient with human immunodeficiency virus on highly active antiretroviral therapy. Int J Obstet Anesth 21: 367-370.

7. García-Lázaro M, Cano A, Vidal E, Rivero A, Kindelán JM (2006) Pain in the lower limbs of a patient with AIDS. Clin Infect Dis 42: 392-393, 428-30.

8. Al-Khawaja D, Seex K, Eslick GD (2008) Spinal epidural lipomatosis--a brief review. J Clin Neurosci 15: 1323-1326.

9. Cersósimo MG, Lasala B, Folgar S, Micheli F (2002) Epidural lipomatosis secondary to indinavir in an HIV-positive patient. Clin Neuropharmacol 25: 51 54.

10. Schürmann D, Rademaker J, Trottenberg T, Bergmann F, Wesselmann $H$, et al. (2005) Spinal epidural lipomatosis: a manifestation of HAART-associated lipodystrophy. AIDS 19: 2052-2054. 